\title{
Co-operation, a Solution to Health Service Provision Problems in Tanzania: Case of the Co-operated Health Care Facilities in Dodoma Region
}

\author{
Mshana Zainabu M. ${ }^{1,}$, , Sinda Hussein S. ${ }^{2}$, Lung'wecha Daudi M. ${ }^{1}$ \\ ${ }^{1}$ Department of Mathematics, Humanities and Social Sciences, National Institute of Transport, Dar es Salaam, Tanzania \\ ${ }^{2}$ Department of Development Studies, Kampala International University, Dar es Salaam, Tanzania \\ Email address: \\ mussa.zainabu@yahoo.com (Mshana Z. M), sindash2003@yahoo.co.uk (Sinda H. S), daudimn@yahoo.com (Lung’wecha D. M) \\ ${ }^{*}$ Corresponding author

\section{To cite this article:} \\ Mshana Zainabu M., Sinda Hussein S., Lung'wecha Daudi M. Co-operation, a Solution to Health Service Provision Problems in Tanzania: \\ Case of the Co-operated Health Care Facilities in Dodoma Region. Science Journal of Public Health. Vol. 4, No. 4, 2016 , pp. 312-320. \\ doi: $10.11648 /$ j.sjph.20160404.17
}

Received: June 3, 2016; Accepted: June 18, 2016; Published: June 29, 2016

\begin{abstract}
The co-operation between Government (GVT) and Faith-Based Organizations (FBOs) in health services provision (HSP) is vital in Tanzania. However, to benefit from such co-operation it requires adoption of the procedures that will overcome the persisting problems of health services provision. The study on the evaluationof the solution to health services provision problems in Tanzania was conducted in Dodoma region. Basically; it analysed the status, problems, reasons for problems and solution of health services provision problems in Dodoma urban and Kondoa districts by targeting GVT and FBOs co-operated health care facilities. Cross-sectional research design was used during the study. Sample size was 394. This was obtained purposively followed by simple random sampling techniques. Both descriptive and inferential statistical analyses were used to analyse the data obtained through questionnaire survey, interview, focus group discussion and participant observation. The sudy identified that the co-operation between the GVT and FBOs in health services provision is important. However, it will be achieved if and only if the moderate status of health services provision in the region will follow various procedures including; analysis of the root causes of the moderate status of health services provision, analysis of the environmental conditions facing GVT and FBOs co-operated health care facilities and, the implementation capability of the GVT and FBOs co-operated health care facilities in Dodoma urban and Kondoa districts. The study recommended that, the Government of Tanzania in co-operation with Faith-Based Organizations should ensure; strong leadership and management team, improvement of infrastructure and working facilities, good management of health plan, availability of essential drugs with reasonable costs and the availability of human resources.
\end{abstract}

Keywords: Co-operation, Health Services Provision, Government, Faith-Based Organizations and Health Care Facilities

\section{Introduction}

Faith-Based Organizations (FBOs) in co-operation with the Government (GVT) have been succeeding to various positive effects. Among others, the co-operation has resulted into prospering economies, increased standard of living and greater global security [24]. The World Health Organization (WHO) report of 2007 pointed that, greater co-operations between the GVT and FBOs are essential in scaling up HIV/AIDs prevention, treatment and care.
FBOs co-operate with the Tanzanian GVT in different activities to improve the well-being of the society. According to [9], there are three areas where FBOs co-operate with the GVT. First, it complements efforts of the GVT such as carrying out works which fit with the GVT policy. If the GVT provides health services in urban areas, FBOs work on the same but in rural areas. The second way is through supplementing efforts of the GVT such as carrying out work beyond what the GVT is able to do. For example, if the GVT wants to extend family planning activities to 107 districts but has a capacity to cover 80 districts, then FBOs make up the 
reference. The third way is through provision of alternative to the GVT policies. When FBOs disagree with the GVT policies and practices, they can show alternative ways of reaching the same goal, for example, convincing the GVT to change the rules (lobbying) [9].

Individuals and families served by the co-operation between the GVT and the FBOs health care facilities receive various benefits [23]. They include culturally and linguistically competent primary and preventive health care and health education services; improved health outcomes because services are provided in contexts that build trust leading to consistent follow-up; better connections with community support networks to provide treatment and sustain healthy lifestyle changes; inclusion of spirituality in beliefs and practices related to health and healing; convenience when services are provided closer to home and at flexible times; and health care providers who have an understanding of the interactions between health issues and an individual patient's constraints based on religious and spiritual beliefs, values and practices. The benefits of partnership between FBOs and GVT health care facilities is to effectively meet the mission of providing the services and supports that lead to increased access and better health outcomes for the populations served.

Other benefits resulted from the co-operation between GVT and FBOs include improved health of citizens, the creation of health care related jobs and the purchase of goods and services that provide for economic reciprocity within communities; and consortium of key community stakeholders who can participate in other planning and program efforts that can strengthen the community safety net [23]. Thus, the cooperarion between GVT and FBOs can be a solution to health services provision problems within the society. However, it is not well known to happen in Tanzania as health service provision is still unfavourable $[12,13,14,16,19]$. Hence, the study evaluated if the co-operation is a solution to health services provision problems in Tanzania by targeting the GVT and FBOs co-operated health care facilities of Dodoma region.

\section{Materials and Methods}

\subsection{Description of the Study Area}

The study was conducted in Dodoma urban and Kondoa districts of Dodoma region, Tanzania. Dodoma is one of the 30 regions in Tanzania. It is almost centrally located on the Tanzania Mainland lying between $5^{\circ} 30^{\prime}$ and $7^{\circ}$ Latitude and the $36^{\circ}$ Longitude line. The region is administratively divided into seven districts namely: Dodoma urban, Dodoma rural, Bahi, Chamwino, Kondoa, Mpwapwa and Kongwa [17]. It is among the five poorest regions in Tanzania Mainland [18]. As illustrated by [18] as well as [16], health services provision in the region is unfavorable. This is due to the presence of high maternal mortality rate, high under-five mortality rates and high prevalence rate of HIV/AIDS. Hence, the study was conducted in the two districts to evaluate the solution of health service provision problems in the region.

\subsection{Research Methods}

A cross-sectional research design was used during the study. While questionnaire survey, interview and participant observation methods were used to collect the primary data in the field, secondary data were obtained through reading extensively various published and unpublished materials. These were books, journals, periodicals, abstracts, indexes, directories, research reports, conference papers and annual reports, internal reports of FBOs, newspapers and magazines from paper-based sources. Internet, videos, televisions and broadcasts were the electronic sources. Cluster sampling followed by the simple random sampling technique was used to obtain a sample size of 394 respondents (169 from Dodoma urban district and 225 from Kondoa district). The sample size was calculated using the equation 1 below:

$$
\mathrm{n}=\frac{z^{2} p q}{d^{2}} \quad \text { Equation } 1 \text { [6] }
$$

Where;

$\mathrm{n}=$ Sample size when population is greater than 10,000 .

$\mathrm{z}=$ Standard normal deviate, set at $1.96(\approx 2.0)$ corresponding to $95 \%$ confidence level.

$\mathrm{p}=$ Proportion in the target population estimate.

$\mathrm{d}=$ Degree of accuracy desired, set at.05 or.02.

$q=1.0-P$.

$\mathrm{p}=\frac{\text { population of two districts }}{\text { total population of the region }}$

$\mathrm{p}=\frac{754271}{1698996}=4.44$

$\mathrm{q}=1-0.44=0.56$

$\mathrm{n}=\frac{2^{2} \mathrm{pq}}{\mathrm{d}^{2}}$

$\mathrm{n}=\frac{2^{2}(0.44 \times 0.56)}{0.05^{2}}=\frac{0.985}{0.0025}=394$

Therefore, respondents in the two districts were 394 people.

Sample size for individual district, respondents was calculated as follows.

In Dodoma Urban district,

$$
\mathrm{n}=\frac{324447}{754271} \times 394=169 \text { respondents }
$$

In Kondoa district,

$$
\mathrm{n}=\frac{429824}{754271}=225 \text { respondents }
$$

The cleaned data were entered to the computer program (SPSS) window version 16.0 software before analysis which was strictly based on the descriptive and inferential statistical analysis.

For descriptive analysis, the measures of central tendency 
such as means and frequencies of critical variables were used to assess the status of health services provision, the strategies and solutions to overcome the problem of health services provision in the two districts. For the inferential statistical analysis, the T-test distribution was used to test the difference in performance between districts at $95 \%$ confidence level. Binary logistic regression models were also developed to determine the main reason of health services provision problems in the GVT and FBOs co-operated health care facilities. The models represent the probability of an event to occur whereas the probability of the event not to occur is given as pro (no event) $=1$-pro (event). The binary logistic regression models comprising more than one independent variable are given as shown in equation 2 [6].

$\mathrm{Yi}=1 / 1+$ ezj (Equation 2).

Where: $\mathrm{Yi}=$ dependent variable depicting the reasons of health service provision problems.

$\mathrm{zj}=$ the combination of influencing factors (independent variables) i.e. $\beta 0 \mathrm{j}+\beta \mathrm{j} 1 \mathrm{Xj} 1+\beta \mathrm{j} 2 \mathrm{Xj} 2+\ldots \beta \mathrm{j} \mathrm{pXj}$.

$\beta 0=$ Constant term of the model without the independent variables.

$\beta=$ independent variable coefficient showing the marginal effects (positive or negative) of the unit change in the independent variables on dependent variable.

$\mathrm{e}=$ is the base of natural logarithm, approximately exp $=$ 2.71828 .

$\mathrm{p}=$ total number of independent variables.

$\mathrm{X} 1$ to $\mathrm{Xp}=$ independent variables.

Binary logistic regression model which is a binary technique for estimating the probability of an event to occur was adopted because of the dichotomous nature of dependent variable and nominal and numerical nature of independent variables [27]. Various indicators such as drugs availability, distances from the patient's home to health care facilities, availability of doctors and nurses, number of hospitals and dispensaries in relation to the available population were used to measure health services provision situation in the selected districts.

\section{Results and Discussion}

\subsection{Analysis of Situation of HSP in GVT and FBOs Co-operated HCFs}

\subsubsection{Status of HSP in GVT and FBOs Co-operated HCFs}

The performance status of health services provision under the co-operation between GVT and FBOs health care facilities showed moderate status. This was mentioned by $153(44.7 \%)$ respondents, good performance by 59 (17.3\%) respondents while those who did not know the performance status also ranged higher by $105(30.7 \%)$ respondents as indicated in figure 1.

Additionally, results on $\mathrm{T}$-test indicated no significant difference $(\mathrm{P}>0.05)$ in the performance status of health services provision in health care facilities operated under the co-operation between GVT and FBOs in the two districts. Thus, the status of health services provision in health care facilities operated under the co-operation between GVT and FBOs are more balanced (moderate status) in both districts as shown in Table 1.

Table 1. T-Test results to compare the status HSP in the two districts.

\begin{tabular}{llllll}
\hline Variable & District & n & Mean & Std.Deviation & Sig. (2.tailed) \\
\hline Status of HSP by GVT and FBOs co-operated HCFs & Dodoma Urban & 143 & 3.37 & 1.664 & $.192 \mathrm{~ns}$ \\
& Kondoa & 199 & 3.62 & 1.830 & \\
\hline
\end{tabular}

Source: Fieldwork Survey, 2012

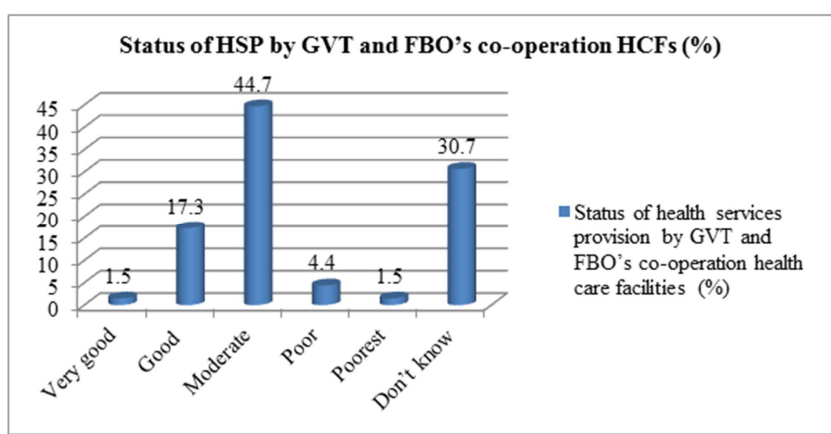

Source: Fieldwork Survey, 2012

Figure 1. Status of HSP problems in GVT and FBOs co-operation HCFs.

\subsubsection{The Presence of HSP Problems in GVT and FBOs Co-operated HCFs}

Figure 2 indicates that, $92(26.9 \%)$ respondents were not aware of the presence of the problems in health services provision at GVT and FBOs co-operated health care facilities. Only $118(34.5 \%)$ agreed with the presence of health services provision problems in the GVT and FBOs cooperated health care facilities. While a large percent, 132 $(38.6 \%)$ argued that, there were no problems in such cooperation.

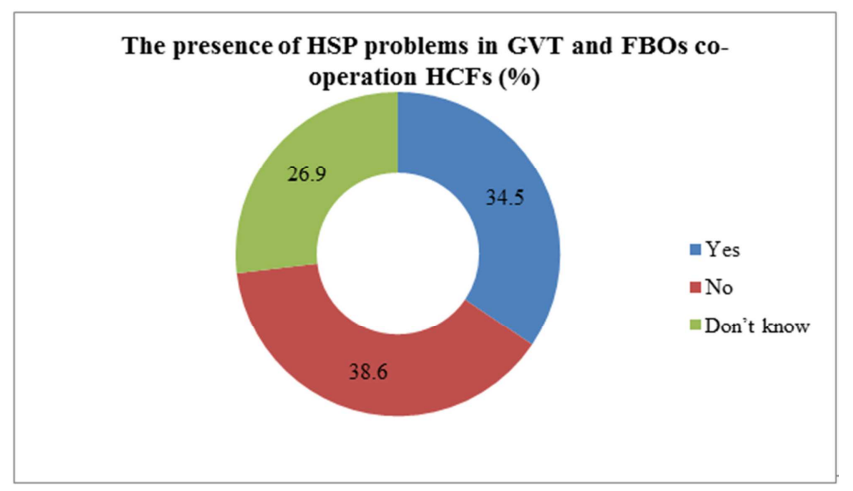

Source: Fieldwork Survey, 2012

Figure 2. The presence of HSP problems in GVT and FBOs co-operated HCFs. 


\subsubsection{Problems of HSP in GVT and FBOs Co-operated HCFs}

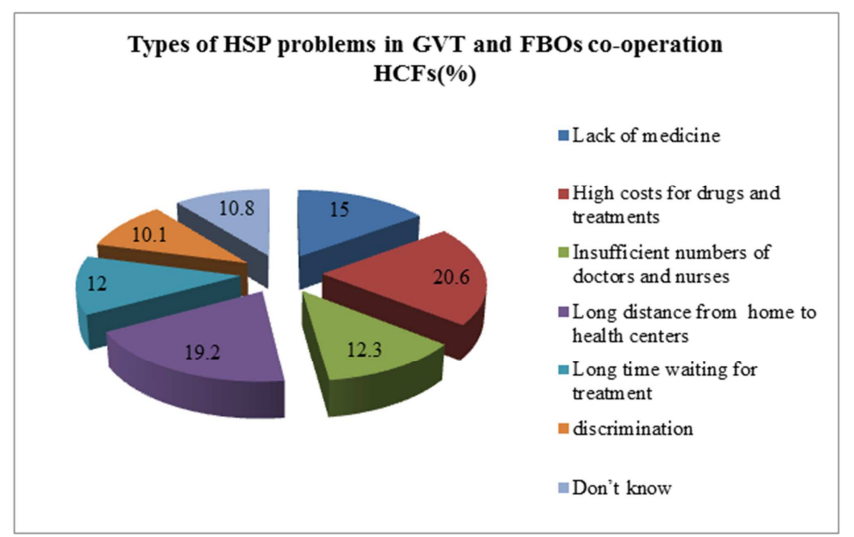

Source: Fieldwork Survey, 2012

Figure 3. HSP problems in GVT and FBOs co-operated HCFs.

It was identified that the leading problem of health service provision in the GVT and FBOs co-operated health care facilities were high costs for drugs and other treatments as mentioned by $99(20.6 \%)$ respondents, long distances from home to health care facilitiesby 92 (19.9\%) respondents, indicating that, there are few GVT health care facilities cooperating with FBOs in Dodoma urban and Kondoa districts. Other problems are insufficient numbers of doctors and nurses mentioned by $21(12.3 \%)$ respondents, discrimination as indicated by one $(10.1 \%)$ respondent and long waiting time for treatment by $19(12 \%)$ respondents as it is indicated in Figure 3. These findings are in agreement with the findings of [19] who pointed out that, high costs for health services and the absence of qualified personnel are the main problems of health services provision at primary health care facilities in Tanzania. Therefore, this reduces health services provision in Dodoma urban and Kondoa districts.

\subsubsection{Reasons for HSP Problems in GVT and FBOs Co-operated HCFs}

The study used binary logistic regression analysis model to identify the main reasons of health service provision problems in GVT and FBOs co-operated health care facilities of Dodoma urban and Kondoa districts. Factors tested were: running costs, budget in the health sector, infrastructure and business oriented notion, management of health plans, and ethical conducts for workers, health education to patients and health care facilitiesas well as income of the society. These factors were used as independent variables in the model as it is indicated in Table 2.

Note: From Table 2, the model -2Log Likelihood = 357.967 ; model chi-square $=82.744$ at $\mathrm{p}<0.05$; overall percentage $=65.5 \%$; number of cases $=342$; Nagelkerke Rsquare $=0.297 ; \beta=$ regression coefficient; $\mathrm{SE}=$ standard error of the estimate; Wald = Wald statistics depicting relationship between dependent and independent variables; $\mathrm{df}$ $=$ degree of freedom; $\operatorname{Exp}(\beta)=$ odds ratio (probability of even to occur over probability of not occurring); $\mathrm{Sig}=$ significance level or $\mathrm{p}$ values; $*=$ statistically significant at $\mathrm{p}<0.05$ level and $\mathrm{ns}=$ non-significant at $\mathrm{p}<0.05$ level of significance.

Table 2. Reasons for problems of HSP in GVT and FBOs co-operated HCFs.

\begin{tabular}{|c|c|c|c|c|c|c|}
\hline Variables & $\boldsymbol{\beta}$ & S.E & Wald & df & Sig & $\operatorname{Exp}(\beta)$ \\
\hline Running costs & .278 & .129 & 4.639 & 1 & $.031 *$ & .757 \\
\hline Budget in the health sector & -.277 & .124 & 5.008 & 1 & $.025 *$ & .758 \\
\hline Infrastructure & .003 & .120 & .001 & 1 & $.982 \mathrm{~ns}$ & 1.003 \\
\hline Business oriented & -.305 & .145 & 4.422 & 1 & $.035 *$ & .737 \\
\hline Management of health plans & -.097 & .126 & .596 & 1 & $.440 \mathrm{~ns}$ & .908 \\
\hline Ethicalconduct for workers & -.047 & .119 & .153 & 1 & $.696 \mathrm{~ns}$ & .954 \\
\hline Health care facilities & .227 & .130 & 3.055 & 1 & $.080 \mathrm{~ns}$ & 1.254 \\
\hline Income of the society & .603 & .125 & 23.389 & 1 & $.000 *$ & 1.837 \\
\hline Constant & .092 & 1.141 & 0.006 & 1 & $.939 \mathrm{~ns}$ & 1.096 \\
\hline
\end{tabular}

Source: Fieldwork Survey, 2012

The $-2 \log$ likelihood of 357.967 presented in Table 2 implied good fitness of data to the model, whereas the overall percentage of $65.5 \%$ signifies correct predictions of independent variables by the model. The model chi-square of 82.74 at 9 degrees of freedom and $p<0.05$ implies significant influence of the independent variables on the dependent variable.The Wald statistics determine whether particular independent variable has significant effects on the dependent variable. In this regard, four factors were significantly likely to affect health services provision in GVT and FBOs co-operated health care facilities in Dodoma urban and Kondoa districts as it is indicated in Table 2. These are; running costs with $\mathrm{p}=0.031$, budget in the health sector with $\mathrm{p}=0.025$, business oriented with $\mathrm{p}=0.035$ and income of the society in Dodoma urban and Kondoa districts with $\mathrm{p}=$ 0.000 .

Furthermore, in the analysis it was found out that, other independent variables do not have significant effects on health services provision by GVT and FBOs co-operated health care facilities of Dodoma urban and Kondoa districts. These independent variables were: infrastructure with $\mathrm{p}=$ 0.982 , health care facilities with $\mathrm{p}=0.080$, management of health plans with $\mathrm{p}=0.440$, health education with $\mathrm{p}=0.077$ and ethical conducts for workers with $p=0.696$. The analysed independent variables were further discussed in the sections below; 


\section{Running costs}

The results in Table 2 revealed a positive regression coefficient $(\beta=0.278)$ between running costs and health services provision in GVT and FBOs co-operated health care facilities in Dodoma urban and Kondoa districts. This implies that, running costs were significantly $(\mathrm{p}=0.031)$ affecting the magnitude of health services provision by a factor of 0.757 . Hence, a unit increases in the running costs increases health service provision costs by a factor of 0.757 and vice versa. Through personal communication with key informants, it was proved that, as running costs in health care facilities increase, costs of health services provision also increase. Thus, as health services provision costs raise the majority who are the poor fail to access health care as the incomes of the society were found to be significant affecting health services provision as indicated in Table 2. Therefore, the increase of running costs in GVT and FBOs co-operated health care facilities affected health services provision in Dodoma urban and Kondoa districts.

\section{Budget in the health sector}

The results in Table 2 have revealed a negative regression coefficient $(\beta=-0.277)$ between budgets in the health sector and health services provision in GVT and FBOs co-operated health care facilities of Dodoma urban and Kondoa district. This implies that, a unit decrease of budgetin GVT and FBOs co-operated health care facilities was significantly ( $\mathrm{p}=$ 0.025 ) decreasing the magnitude of health services provision by a factor of 0.758 and vice versa. These findings concur with those of [21] who reported that, the health budget in Tanzania is not adequate enough to ensure resources availability in health care facilities. Therefore, insufficient budget in the health sector reduces the efficiency of health services provision in GVT and FBOs co-operated health care facilities in Dodoma urban and Kondoa districts.

\section{Infrastructure and working facilities}

Although not significant $(\mathrm{p}=0.982)$, infrastructure affected health services provision in GVT and FBOs co-operated health care facilities by a factor of 1.003 as it is indicated in Table 2 . Having positive regression coefficient $(\beta=0.003)$ means that, 1 unit increase of infrastructure increases health services provision by a factor of 1.003 and vice versa. These findings are supported by $[8,15,10]$ who argued that, the precence of poor infrastructure affects health services provision positively. Hence, poor infrastucture reduces health services provision in GVT and FBOs co-operated health care facilities in Dodoma urban and Kondoa districts.

\section{Businesses oriented notions}

Table 2 shows a negative regression coefficient $(\beta=$ $0.305)$ of business oriented notion. This implies that, business oriented notions significantly $(p=0.035)$ affects health services provision in health care facilities operated under the co-operation between GVT and FBOs. The results showed that, a decrease in 1 unit of business orientation notions in GVT and FBOs health care facilities decreased health services provision by the factor of 0.305 and vice versa. Thus, as institution engages in business it tends to earn profit which will help to cover the running costs and ensure the availability of facilities in a given activity. However, this argument and results are in opposition to those of [10] who observed that, business in health service provision reduces utilization of health services. This is because these facilities provide services at high prices as they aim at profit maximization. Hence, these reduce access and utilization of health care facilities in the two districts.

\section{Management of health plan}

Although not statistically significant $(\mathrm{p}=0.440)$, management of health plans affects health services provision in GVT and FBOs co-operated health care facilities by a factor of 0.908 as it is indicated in Table 2. A negative sign of regression coefficient $(\beta=-0.097)$ implies that, one unit decrease of management of health plans decreases health services provision in GVT and FBOs co-operated health care facilities by a factor of 0.908 and vice versa. These results are in line with [20] and [3] who reported that, strong management is a determinant of success in any activity. Hence, poor management of health plans reduced health services provision in GVTand FBOs co-operated health care facilities of Dodoma urban and Kondoa districts.

Ethical conduct for workers

Table 2 shows a negative regression coefficient $(\beta=$ 0.047) of ethical conduct for workers. This implies that, decrease in one unit of ethical conduct for workers at $p=$ 0.696 decreases health services provision in GVT and FBOs co-operated health care facilities by the factor of 0.904 . Hence, ethical conduct for workers affects health services provision in Dodoma urban and Kondoa districts. These results are supported by [1 and 5] who found out that, abusive and harassment behaviours of health workers were known to be barriers to access and utilization of services within a community. Therefore, the absence of ethical conduct increased health services provision problems in Dodoma urban and Kondoa districts.

\section{Health education of the patients}

Table 2 shows a positive regression coefficient $(\beta=0.160)$ of health education of the patients. This implies that the increase in lunit of health education to the patient at $\mathrm{p}=$ 0.077 increase health services provision in GVT and FBOs co-operated health care facilities by the factor of 0 . 805, while the decrease of health education to the patient decreases health services provision by a factor of 0.805 . These findings are supported by [4] who identified that, education of the household head is vital in making health decisions. Furthermore, [11] argued that health education to the patients help understanding of diseases better and cooperate with the medical sevices so that they carry out treatment properly. Health education can also teach new knowledge about how to prevent diseases such as malaria and gastroenteritis. Therefore, lack of health education to the patient reduced health services provision in Dodoma urban and Kondoa districts.

Health care facilities

Table 2 shows a positive regression coefficient $(\beta=0.227)$ of health care facilities. This implies that, the increase of 1 unit of health care facilities at $p=0.080$ increases health 
services provision in the two districts by a factor of 1.254 and vice versa. These findings are supported by [7] who made a study on the relationship between workload and health worker performance. In his study he found out that, when the number of patients per health worker grows sufficiently high, there will be insufficient time to diagnose and treat all patients adequately. Therefore, high population growth compared with the available health care facilities reduced health services provision in GVT and FBOs co-operated health care facilities of Dodoma urban and Kondoa districts.

Incomes of the society

Table 2 shows a positive regression coefficient $(\beta=0.603)$ of income of the society and health services provision in GVT and FBOs co-operated health care facilities. This implies that, the increase in 1 unit of income for the society significantly $(p=0.000)$ increase health services provision in GVT and FBOs co-operated health care facilities by a factor of 1.837 and vice versa. These results are supported by [25] who reported that, if the society has low income it also fails to get health services and vice versa. Therefore, insufficient income of the society reduced access and utilization of health services in GVT and FBOs co-operated health care facilities of Dodoma urban and Kondoa districts.

\subsection{Solution of HSP Problems in GVT and FBOs Co-operated HCFs}

Co-operation in providing social services is of particular importance and plays a big role in public life [28]. There is co-operation between the GVT and FBOs health care facilities in establishing and operating jointly to increase the availability of health services in Dodoma urban and Kondoa districts. However, findings in this study indicated problems and reasons for health services provision problems in the two districts. If those problems are not solved the health services provision will not be sufficient even if there is good cooperation in the two districts. Thus to overcome the problems various procedures (as were adopted and modified from [22] and summarized in Figure 4) must be considered. These are as follows:

(1) The root causes of the moderate status of health services provision,

(2) Environmental conditions facing GVT and FBOs cooperated health care facilities and,

(3) The implementation capability of the GVT and FBOs co-operated health care facilities in Dodoma urban and Kondoa districts.

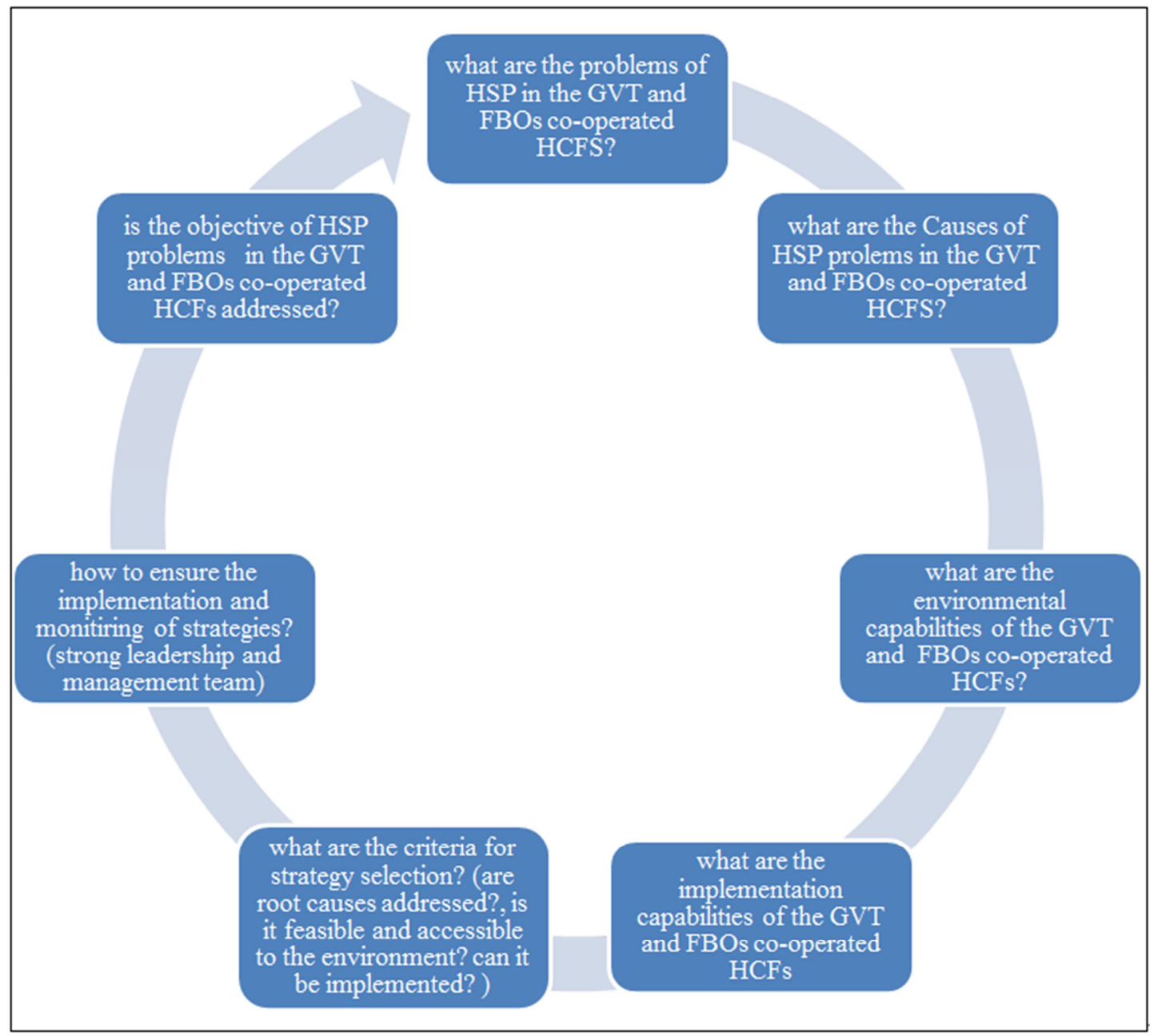

Source; modified from [22].

Figure 4. Conceptual framework for procedures of addressing HSP problems in the GVT and FBOS co-operated HCFs. 
(1) Root causes of the moderate status of health services provision

Through the findings presented in this study, the root causes of health services provision problems in Dodoma urban and Kondoa districts were; running costs, budget in the health sector, infrastructure and business oriented notion, management of health plans, ethical conducts for workers, health education to patients and health facilities and income of the society. The solution to overcome health services provision problems will be achieved by considering the mentioned root causes, environmental conditions and the implementation capability of the GVT and FBOs co-operated health care facilities as discussed hereunder.

(2) The environmental conditions of the GVT and FBOs co-operated HCFs

The identified causes of health services provision in the two districts should be solved by considering the environmental condition of the GVT and FBOs co-operated health care facilities such as distribution of power in health sector, prevailing market structure, cultural and community norms, health services financing and payment systems and the availability of physical infrastructures (transportation and telecommunication works).

Power distribution: the power distribution should allow management of each health care facility to conducts all activities including: ensuring availability of all essentials facilities as described by Tanzanian health services provision guide of 1996 and availability of staff members who are proportional to the patients per day. This will be achieved by the Ministry through providing the requested budget to the health care facility as per requirements.

Prevailing market structure: There should be an assessment to identify the needs and demand for the society. The assessment will help to understand kind of services people required at a given period of time.

Cultural and community norms: Culture and community norms create a unique pattern of beliefs and perceptions as to what "health" or "illness" actually mean. In turn, this pattern of beliefs influences how symptoms are recognized, to what they are attributed and how they are interpreted, how and when health services are sought. Cultural differences in the recognition and interpretation of symptoms and in the use of health services are necessary aspects in assurance of health services provision. From [2] the author identified that, although pain was considered a biological phenomenon, sensitivity to pain and attributing significance to pain symptoms varied by culture and community. He also identified that, delay in seeking care was found among individuals belonging to cultural groups characterized by ethnic exclusivity, traditional family authority, and high skepticism about medicine. Consideration of cultural and community norms in health services provision therefore, is integral to health services because it will assure the provision of appropriate services and reduce the incidence of medical errors resulting from misunderstanding caused by differences in culture. Cultural and community norms also have potential for improving the efficiency of care by reducing unnecessary diagnostic testing or inappropriate use of services.

Health services financing and payment systems: Payment systems play a critical role in determining health system performance in so far as they influence the supply and demand of health care. On the supply side, payment influences how providers enter the market and how services will be produced; and on the demand side, patients often decide what to purchase and how much to consume, based on the amount they have to pay. Thus, budget in the health sector should be sufficient enough to make services sustainable. Likewise in GVT, FBOs also have a responsibility of ensuring availability of funds for health services provision especially for the majority who are poor to achieve quality care. This is because poor quality care generates unnecessary costs through the underuse, overuse, and misuse of interventions and services. Moreover, quality improvements will not automatically flow either from the good intentions or training of health care professionals but how to improve the provision of health services to achieve improved patient outcomes and to optimize financial outcomes. Therefore, policy and planning for financing of health should concern with how funding is made available and allocated in the health sector in order to avoid unnecessary costs which will finally lead to persistence of health services provision problems.

The availability of physical infrastructure: Distance to the nearest facility is an important factor in planning for health services provision. Health care facility must be located within a reasonable distance, and the cost of seeking service should be affordable for equitable health care provision. This will avoid loss of time and money. Furthermore, telecommunication (telephones, cellular phones, two-way radios and internet) is essential for emergency referrals to higher levels of care. This is essential for the transmission of important data, epidemic alerts, administrative and management support. Hence, increase of prevention of various diseases and assurance of healthier population.

(3) Implementation capability

Inorder to achieve the suggested solutions to overcome the problem of health services provision, the GVT and FBOs should be able to attract and deploy resources required to achieve the intended objectives. They included readiness of institution to change such as the allocation of funds to be proportional with the growth of population, the quality and qualification of the institution's human resources, the distribution of formal and informal power within the institution, the institution's financial stability and the extent of its technology, equipment and supplies.

\section{Conclusions, Policy Implications and Recommendations}

The situation of health services provision in GVT and FBOs co-operated health care facilities is of moderate status. 
There were problems such as high costs for drugs and other treatments, long distances from home to health care facilities, insufficient numbers of doctors and nurses, discrimination and long waiting time for treatment. It was identified that these problems were facilitated by; running costs, budget in the health sector, infrastructure, business oriented notions, management of health plans, ethical conducts for workers, health education to patients and health care facilities as well as income of the society. Findings in this study recommended that co-operation in health services provision between the GVT and FBOs health care facilities in Dodoma region is of essential importance. However, the positive achievement of solving the problems should follow the analysed strategies including; the root causes of the moderate status of health services in health care facilities, environmental conditions facing the co-operated health care facilities between the GVT and FBOs and the implementation capability of the GVT and FBOs co-operated health care facilities. Furthermore, the Government of Tanzania in co-operation with Faith-Based Organizations should ensure strong leadership and management team. This will: assist in the availability of health care facilities that are proportional with the need of the growing population; ensure improvement of infrastructure and working facilities; ensure good management of health plan; ensure availability of essential drugs with reasonable costs and the availability of human resources.

\section{References}

[1] Amooti-Kaguna, B and Nuwaha, F. (2000), Factors influencing choice of delivery sites in Rakai district of Uganda, Social Science and Medicine, Vol. 50, No. 23, 203-213.

[2] Anderson, L. M. Scrimshaw, S. C. Fullilove, M. T. Fielding, J. E and Normand, J. (2003), Culturally Competent Healthcare Systems: A Systematic Review, American Journal of Preventive Medicine, Vol. 2, No 3, 657-658.

[3] Caldoe, J. (2001), seven e-government leadership milestones. In forthcoming book, vision and revision [http://01.ibm.com/industries/government/ieg/pdf/seven-egovmilestones.pdf], site visited on 12/04/2012.

[4] Gounder, R and Xing, Z. (2012), Impact of education and health on poverty reduction: Monetary and nonmonetary evidence from Fiji, Economic modeling, Vol. 29, No. 3, 787794.

[5] Grossmann-Kendall, F. Filippi, V. De Koninck, M and Kanhonou, L. (2001), Giving birth in maternity hospitals in Benin: Testimonies of women. Reproductive Health Matters, Vol. 9, No. 18, 90-98.

[6] Kothari, C. R. (2005), Research Methodology: Methods and Techniques. Second Edition, New Age International Publishers, Washington DC.

[7] Maestada O. Torsvikb, G and Aakvikc, A. (2010), Overworked? On the relationship between workload and health worker performance, Journal of Health Economics, Vol. 29, No. 5, 686-698.

[8] Mamdani, M and Bangser, M. (2004), Poor people's experiences of health services in Tanzania: A literature review, Reproductive health matters, Vol. 12, No. 20, 138-153.

[9] Massawe, N. M. (2002), Organizational Development Manual, TANGO, Tanzania.

[10] Matsuokaa, S. (2010), "Perceived barriers to utilization of maternal health services in rural Cambodia" Cambodia.

[11] Moran A. C. (2007), Patterns of maternal care seeking behaviors in rural Bangladesh, Tropical Medicine and International Health, Vol. 12, No. 7, 823-832.

[12] Mshana, Z. M, Zilihona, I. J. E, Gesase, A. P, Sinda, H. S, Nsimba, S. E. D, (2013). Health Services Delivery and the Increase of Poverty in Tanzania: The Invisible Factor, World Research Journal of Public Health and Epidemiology Vol. 1, No. 1, 2013, PP: 01-12 Available online at http://scitecpub.com/Journals.php

[13] Mshana, Z. M, Nsimba, S. E. D and Gesase, A. P (2014). Factors Affecting Health Service Provision in Tanzania: Case of Public Primary Health Care Facilities in Dodoma Region, International Research Journal of Natural and Applied Sciences(IRJNAS), Volume-1, Issue-7 (ISSN: (2349-4077)

[14] Mshana, Z. M, Zilihona, I. E., Canute, H. B, (2015). Forgotten Roles of Health Services Provision in Poor Tanzania: Case of Faith Based Organizations' Health Care Facilities in Dodoma Region. Science Journal of Public Health, Vol. 3, No. 2, pp. 210-215.

[15] Mwaikambo, E. (2010), Improving maternal, newborn and child health in Tanzania: From science to action, A presentation on Paediatrics and Child Health at Hubert Kairuki Memorial University on $5^{\text {th }}$ February, 2010.

[16] Nassoro, M (2008) "Dodoma Regional Annual Plan 2010201”, Dodoma General Hospital. Dodoma, Tanzania.

[17] National Bureau of Statistics (NBS), (2002), Household budget of 2001, Dar es Salaam, Tanzania.

[18] National Bureau of Statistics (NBS)(2009), Dodoma Regional Socio-Economic Profile: Ministry of Planning, Economy and Empowerment, $2^{\text {nd }}$ Edition, Dar es Salaam [http://www.tanzania.go.tz/regions/dodoma/pro], site visited on $01 / 09 / 2010$.

[19] Nsimba, S. E. D, Massele, A. Y, Erikson, J. Gustaffson, L. Tomson, G and Warsame, M. Y. (2002), Case management of malaria in under - fives at primary health care facilities in a Tanzanian district, Tropical medicine and International health, Vol. 7, 201-209.

[20] OECD. (2003), Checklist for e- Government leaders [http://www.oecd.org/dataoecd/62/58/11923037.pdf], site visited on 10/04/2012.

[21] Olenguruma, O (2012) Challenges facing the ministry of health and social welfare in Tanzania, ISSN 0850-7573, No.04420.

[22] Pallas, W. S. Curry, L. Bashyal, C. Berman, P and Bradley, E. H. (2010), improving health services delivery organizational performance in health system: taxonomy of strategy area and conceptual framework for strategy selection, International Health, Vol. 4, No. 1, 20-29.

[23] Polycarp, R, L. (2001), Sprituality and faith in health care delivery, Health center management, Vol. 38, No. 22, 54-66. 
[24] Rutzen, D. B. (2001), Symposium: NGO-Government Partnerships in Central and Eastern Europe and the former Soviet Union, The international Journal of Not-for Profit Law, Vol. 3, No. 4, 26-29.

[25] Sachs, J. (2005), The End of Poverty, The Penguin Press, New York.

[26] WHO. (2007), Towards Primary Health Care: Reviewing partnership with Faith-Based Communities and services, WHO, Geneva.
[27] Wuensch, K. L. (2008), Binary logistic regression with Statistical Package for SocialScience, [http://core.edu.edu/pspc/wuenschk/spss/spss-mv.htm], sitevisited on 14/2/2009.

[28] Douglas, B. (2003), The reliability and validity of willingness to pay measure formaternity services in Vietnam, The International Journal of Not-for-ProfitLaw, Vol. 3, No. 4, 4761 . 